\title{
COMUNICAÇÃO PÚBLICA PARA CIDADANIA NO AVANÇO DAS REDES SOCIAIS OFICIAIS
}

\author{
PUBLIC COMMUNICATION FOR CITIZENSHIP \\ IN THE ADVANCEMENT OF THE OFFICIAL SOCIAL NETWORKS \\ COMUNICACIÓN PÚBLICA PARA LA CIDADANÍA \\ EN EL AVANCE DE LAS REDES SOCIALES OFICIALES
}

Danilo Rothberg

Dr, UNESP

danroth@uol.com.br

\author{
Amanda da Silva Valença \\ Graduada, UNESP \\ amandavalenca.rp@gmail.com
}

\begin{abstract}
Resumo: O avanço da exploração das redes sociais por governos pode gerar iniciativas de comunicação pública capazes de contribuir para o aprofundamento da cidadania, pensada como exercício do direito à informação sobre gestão pública. Este artigo descreve resultados de pesquisa que avaliou, através de análise de conteúdo, a abrangência e a profundidade da informação oferecida pelo governo do Estado de São Paulo em textos noticiosos acessados através das redes sociais Twitter, YouTube, Facebook e Orkut para divulgar propósitos, linhas de ação e limites de políticas públicas de impacto imediato para a cidadania, das áreas de assistência social, saúde, educação e meio ambiente. Os resultados indicam que a amostra analisada contém, em média, entre $28 \%$ e $40 \%$ do total de informações consideradas como necessárias para a caracterização abrangente e plural das políticas públicas enfocadas, segundo o contexto teórico-metodológico da pesquisa.
\end{abstract}

Palavras-chave: democracia digital, mídias sociais, políticas públicas, informação.

Abstract: The advancement in the deployment of social networks by governments can generate public communication initiatives, which may contribute to the strengthening of citizenship, understood as the exercise of the right to information about public management. This article describes results of research which assessed, through content analysis, the breadth and depth of information offered by the state government of São Paulo in news stories accessed through the social networks Twitter, YouTube, Facebook and Orkut which publicize purposes, lines of action and limits of public policies of immediate impact for citizenship, in the areas of welfare, health, education and environment. Results indicate that the analyzed sample contains, on average, from $28 \%$ to $40 \%$ of all information deemed necessary for the comprehensive and plural characterization of a public policy, according to the theoretical-methodological context of the research.

Key words: digital democracy, social media, public policy, information.

Resumen: El avance en la exploración de las redes sociales por los gobiernos puede generar iniciativas de comunicación pública que contribuyen a la profundización de la ciudadanía, concebida como lo ejercicio del derecho a la información sobre la gestión pública. Este artículo describe los resultados de un estudio que evaluó a través de análisis de contenido el 
alcance y la profundidad de la información ofrecida por el gobierno del estado de São Paulo en los textos de las noticias se accede a través de las redes sociales Twitter, YouTube y Facebook para dar a conocer los propósitos, las líneas de acción y los límites de las políticas públicas de impacto inmediato para la ciudadanía, en las áreas de asistencia social, salud, educación y medio ambiente. Los resultados indican que la muestra analizada contiene, en promedio, entre el $28 \%$ y el $40 \%$ de toda la información necesaria para la caracterización integral y plural de las políticas públicas focalizadas, de acuerdo con el marco teórico-metodológico de la investigación.

Palabras clave: democracia digital, medios de comunicación social, políticas públicas, información.

\section{Introdução ${ }^{1}$}

Os governos estão atentos às vantagens que a internet oferece como meio facilitador de comunicação e prestação de serviços aos cidadãos. A instituição de sistemas de governo eletrônico permite que serviços públicos sejam acessados online. Práticas de democracia digital possibilitam que os cidadãos se informem sobre assuntos referentes à gestão pública e dialoguem com o poder público.

Com isso, portais eletrônicos de governos se tornaram alvos de pesquisas que buscam identificar de que forma a comunicação pública é realizada online, com que frequência, qualidade e se realmente corresponde às potencialidades da internet, com abordagens diferenciadas, atendendo os diversos públicos.

A própria internet é um meio dinâmico, que evolui rapidamente. As pesquisas que avaliam o modo como as informações são transmitidas pelos governos na rede e como a comunicação pública é praticada devem ser capazes de captar os meios pelos quais se dão as transformações digitais. De crescente uso na rede são as mídias sociais, mas em curto período de tempo elas podem se esgotar em determinadas possibilidades, ao mesmo tempo em que se recriam, servindo a outras finalidades. Como grande parte dos usuários da rede adere à interação possibilitada pelas mídias sociais online, os governos têm investido em inovadoras experimentações de comunicação pública em canais oficiais nas plataformas Twitter, Facebook, Orkut e Youtube, que têm sido crescentemente acessadas por quem se interessa em saber mais sobre a gestão pública e suas políticas.

A pesquisa descrita neste artigo realizou análises de conteúdo das mídias sociais oficiais do Estado de São Paulo, avaliando a qualidade das informações disponibilizadas pelo

\footnotetext{
${ }^{1}$ Os autores agradecem ao CNPq (Conselho Nacional de Desenvolvimento Científico e Tecnológico) pela bolsa de pesquisa concedida.
} 
governo estadual em textos noticiosos produzidos pelas assessorias de comunicação das diversas instâncias de gestão pública (secretarias, autarquias, departamentos etc) e acessados através daquelas mídias sobre políticas de saúde, educação, assistência social e meio ambiente em relação a 14 categorias: antecedentes; diagnósticos; objetivos; métodos; recursos atuais; ações atuais; recursos panejados; ações planejadas; eficiência; eficácia; impacto; custoefetividade; satisfação do usuário; equidade. O conteúdo das solicitações específicas dos usuários, além das respostas do governo a elas, também foi analisado em relação aos temas mais frequentes.

Os resultados indicam que a amostra de 231 textos analisados contém, em média, entre $28 \%$ e $40 \%$ do total de informações que poderiam ser consideradas necessárias para a caracterização plural e abrangente das políticas públicas enfocadas, segundo o contexto teórico-metodológico da pesquisa. Apesar de o governo estar presente em diversos nichos virtuais e mídias sociais, o conteúdo disponível pode ser considerado insuficiente.

Os resultados também indicam que o meio mais utilizado para críticas, sugestões, indagações e troca de mensagens sobre políticas públicas entre cidadãos e governo é o Twitter, fazendo com que essa plataforma permita o desempenho de funções que usualmente seriam desempenhadas por uma ouvidoria pública, ainda que muitas respostas do governo sejam padronizadas e nem todos os usuários sejam atendidos. No Youtube, não foram encontradas solicitações de usuários, o que sugere que essa mídia social pode não ser eficiente para o governo ou não ser atrativa o suficiente. No Facebook e no Orkut, não foram verificadas respostas específicas às solicitações.

O percurso do artigo se divide em três etapas. Em primeiro lugar, são revisadas teorizações atuais sobre democracia digital, governo eletrônico, esfera pública, comunicação pública e mídias sociais. Em segundo lugar, a metodologia é caracterizada e os resultados empíricos são apresentados e discutidos. Considerações finais sintetizam as contribuições do artigo para a compreensão do estágio atual de exploração potencial da rede como meio potencial para o aprofundamento da cidadania pensada como exercício do direito à informação sobre políticas públicas.

\section{Teorizações fundamentais}

A internet tornou-se uma ferramenta disponível a aqueles que desejam exercer vigilância sobre o poder e usufruir de uma maior diversidade de fontes de informação para saber mais sobre como reivindicar seus direitos. O acesso rápido e fácil a informações 
favorece a criação de esferas virtuais atentas à gestão pública, na forma de "comunidades de interesse" que "marcam um caminho incrivelmente frutífero na transformação do conhecimento especializado, na descentralização do saber e na potencialização da cidadania" (Bustamante, 2010, p. 33).

Para Marques (2006, p. 170), “a internet possui a capacidade de abrigar diversas destas arenas de discussão, pois se trata de uma rede de comunicação pública não necessariamente institucionalizada e, em muitas ocasiões, local que abriga a formação espontânea de opiniões". Se o cidadão deseja estar informado sobre aquilo que se refere a seus direitos, estar consciente sobre como é gasto o dinheiro de seus impostos e sobre como utilizar um serviço público, o governo eletrônico (e-gov) pode atender a essa demanda com a oferta de dados de fácil acesso, aprofundando a transparência governamental, a eficiência de gestão e o combate à corrupção (Dujisin, 2004; Silva, 2010).

As operações do e-gov devem se orientar, segundo Dujisin (2004), em três frentes: oferta de informação e dados abertos; comunicação e interação com usuários; prestação de serviço. E podem ser classificadas em: processo informativo, que esclarece as condições da oferta presencial de um serviço; transação simples, que permite, por exemplo, obtenção de formulários e documentos, inscrições em programas sociais e envio de declarações; e transação complexa, que torna possíveis atividades como a realização de pagamentos de taxas e impostos.

Quando os governos utilizam a internet para construir vias de democratização digital, os níveis de participação do cidadão podem ser: consultivo (os usuários opinam sobre os assuntos de gestão pública, mas não tomam decisões); resolutivo (o governo consulta a opinião dos usuários e as considera eventualmente como input para a tomada de decisão política e administrativa); e deliberativo (os cidadãos interagem efetivamente com a tomada de decisão pela instância de gestão de pública), segundo Dujisin (2004).

A democracia digital pode reduzir a distância entre a esfera política (poder de decidir, de tomar decisões) e a esfera civil (poder de mandar, mas não decidir, de identificar e sinalizar os problemas), conforme Marques (2009), para quem a internet ainda pode minimizar a divergência entre os poderes dos segmentos administrativo (referente à esfera política e à deliberação formal) e comunicativo (referente à esfera civil e à deliberação informal). Ao passo que o segmento comunicativo não tem o poder de governar, sua função está em orientar o uso do poder administrativo, de forma que seu potencial amplia-se com o 
advento da internet e seu emprego para a transparência de gestão, por sua vez essencial para a abertura, colaboração e participação dos cidadãos, tornando a informação sobre políticas públicas mais valiosa através do compartilhamento.

Entende-se por política pública "qualquer ação dos poderes públicos que seja executada a fim de garantir os mais diferentes direitos de cidadãos e cidadãs, segundo o estabelecido no ordenamento jurídico de um país dado" (Godoi, 2007, p. 35).

Um setor investido pelo Estado através da Constituição Federal de 1988 como objeto de políticas públicas foi o social, incluindo questões raciais, de gênero, socioambientais e educacionais. Segundo Godoi (2007), antes as políticas públicas eram voltadas prioritariamente a questões tributárias, diplomáticas, de defesa e segurança interna. No Brasil, os estudos sobre o tema são recentes, e "a ênfase recaiu ou à análise das estruturas e instituições ou à caracterização dos processos de negociação das políticas setoriais específicas" (Trevisan \& Bellen, 2008, p. 531).

A redemocratização inaugurada com a Constituição Federal de 1988 transformou aos poucos a agenda pública, desencadeando entre os diversos setores sociais o desejo de influenciar o planejamento e a execução de ações públicas, apesar dos obstáculos representados por agentes de governo formados no ambiente autoritário anterior. "Se antes o encantamento da imaginação social brasileira era o Estado, nos anos 1990 esse apego passa a ser direcionado, paulatinamente, para a sociedade civil" (Trevisan \& Bellen, 2008, p. 533).

A utilização da internet para disseminação de informações sobre políticas públicas de forma acessível ao público em geral deve levar em conta que muitos cidadãos não possuem conhecimento a respeito dos processos através dos quais elas são formuladas, e assim podem não estar atentos às oportunidades de fazer seus direitos valerem como sujeitos democráticos de sua história. O resultado desta limitação é conhecido: “acabamos por limitar nossa tarefa cidadã de avaliar o desempenho daqueles grupos políticos e/ou indivíduos que disputarão o nosso voto no próximo pleito eleitoral" (Godoi, 2007, p. 34).

As metodologias usuais capazes de gerar informações sobre o desempenho de políticas públicas abrangem estudos de metas e impactos, em quatro tipos: instrumental, que requer a definição de ações baseada nos melhores dados disponíveis e a ampla divulgação dos resultados; conceitual, que gera reflexões sobre a equação estabelecida entre princípios de ação e resultados esperados; instrumento de persuasão, utilizado para mobilizar o apoio nas eventuais mudanças de programas; e esclarecimento, que orienta a agenda governamental 
através do acúmulo de avaliações dos diversos setores sociais (Costa \& Castanhar, 2003; Faria, 2005)

A avaliação da qualidade das informações sobre o desempenho de políticas deve ser realizada por meio da aplicação de critérios e medidas de mensuração de aspectos como eficácia, eficiência, equidade, impacto, padrões de referência, parâmetros normativos, elementos teóricos e expectativas de longo prazo.

A difusão de informações provenientes de avaliações sistemáticas de políticas públicas pode contribuir para ampliar a vigilância sobre a eficiência e a eficácia do setor público, mas ainda não é prevista como instrumento de estratégia, planejamento e execução de programas. Nem sempre a avaliação é vista positivamente pelos gestores. "As avaliações podem ser um 'problema' para os governantes, executores e gerentes de projetos porque os resultados podem causar constrangimentos públicos", lembram Trevisan \& Bellen (2008, p. 533), para quem "as informações e resultados das avaliações podem ser usados pelo público e pela imprensa para criticar os governos, da mesma forma que, em caso de 'boas notícias', os governos podem usá-las para legitimar as próprias políticas, como ganho político etc".

Mas o avanço democrático amplia a exigência de accountability dos governos, ou seja, de transparência na prestação de contas, que possibilita a responsabilização de mandatários pelas políticas que formulam e executam. "Assim como o movimento da nova administração pública vem sofrendo pressões sobre seu caráter democrático-participativo (ou falta dele), está em aberto o debate sobre novas formas de accountability e participação social sobre a avaliação de políticas públicas no contexto democrático brasileiro (Trevisan \& Bellen, 2008, p. 548).

As avaliações geram o dado a ser exposto aos diversos segmentos sociais para fundamentar o debate público sobre como melhorar a política: "os relatórios das avaliações podem servir tanto para divulgação, quanto para fomento do debate público em torno das alternativas de intervenção governamental em uma dada realidade social” (Trevisan \& Bellen, 2008, p. 540).

Para a disseminação de informações sobre políticas públicas, as ferramentas de comunicação pública são essenciais, particularmente em sua identificação como comunicação de Estado e governo, na forma de um "instrumento de construção da agenda pública (que) direciona seu trabalho para a prestação de contas, o estímulo para o engajamento da 
população nas políticas adotadas, o reconhecimento das ações promovidas nos campos políticos, econômico e social” (Brandão, 2007, p. 5).

Monteiro (2007, p. 39), em sua revisão da literatura pertinente, indica o papel da comunicação pública de "responder à obrigação que as instituições públicas têm de informar o público; estabelecer uma relação de diálogo de forma a permitir a prestação de serviços ao público; (...) e integrar o processo decisório que acompanha a prática política".

Nesta conceituação, comunicação pública se dissocia de marketing político, uma vez que é tida como "instrumento de diálogo, interatividade e envolvimento dos cidadãos nas políticas públicas e não como instrumento de promoção pessoal dos agentes públicos" (Monteiro, 2007, p. 34). Deste princípio, decorre a exigência de estabelecimento de critérios para favorecer o debate público, que "corre o risco de privilegiar questões que representem o interesse de um ou mais públicos específicos, desvirtuando, na origem, qualquer utilidade pública que se queira" (Matos, 2007, p. 53). Os riscos são também de "questões pontuais serem defendidas como gerais; interesses particulares se arvorarem como públicos; a fortuita inflação do valor de questões em detrimento de outras; o privilégio de determinadas vias de compreensão e comportamento" (Matos, 2007, p. 54).

Matos (2011, p. 44) assinala que a comunicação pública "não deve ser reduzida apenas a um processo transmissivo e unilateral (envio de informações dos governantes para os governados)", uma vez que deve, diante das exigências da cidadania contemporânea, incluir a criação de espaços de interação e trocas comunicativas entre instituições políticas e sociedade.

A comunicação pública, segundo Duarte (2007, p. 70), assume um caráter cada vez mais pluralista e democrático e "exige também a capacidade profissional de viabilizar padrões adequados que promovam não apenas a divulgação, mas também o acesso à informação e oportunidades de diálogo e participação".

\section{Metodologia}

A amostra provém de 231 páginas web com textos noticiosos sobre políticas das áreas de saúde, educação, assistência social e meio ambiente, produzidos e hospedados pelas assessorias de comunicação das diversas instâncias de gestão do governo do Estado de São Paulo (secretarias, autarquias, departamentos etc), e acessados através das mídias sociais oficiais nas plataformas Twitter (twitter.com/governosp), YouTube (www.youtube.com/user/ 
governosp), Facebook (facebook.com/governodesaopaulo) e Orkut (indisponível após a desativação da plataforma em 30 de setembro de 2014).

Coleta, análise e interpretação de dados foram realizadas entre os meses de outubro de 2011 a abril de 2012. Vídeos disponíveis no YouTube tiveram suas entrevistas e demais dados textuais transcritos. Apenas as informações provenientes do texto verbal foram consideradas.

A análise das informações disponíveis nos textos noticiosos acessados através das mídias sociais selecionadas foi realizada por meio de 14 categorias formuladas de acordo com referenciais da literatura de avaliação sobre políticas públicas (Costa \& Castanhar, 2003; Faria, 2005; Souza, 2003; Trevisan \& Bellen, 2008). As categorias, inicialmente formuladas em pesquisa descrita em Rothberg (2010), foram assim constituídas:

1) Antecedentes: compreende informações que precederam e motivaram a criação e implementação de determinada política. 2) Diagnósticos: o planejamento de uma política envolve os problemas e dificuldades a serem enfrentados. Esta categoria abarca informações que se relacionam a descrição de determinada política, considerações gerais e informações relacionadas às decisões sobre sua adoção. 3) Objetivos: as finalidades que se deseja alcançar a partir da criação e aplicação de uma política pública, de forma geral, sem necessariamente expressar números. 4) Metas: esta categoria se relaciona à presença de números, estatísticas, projeções etc a respeito do que busca atingir em termos quantitativos e escala temporal. 5) Ações atuais: relaciona-se aos procedimentos e ações efetivamente realizadas no tempo presente no âmbito de execução da política; 6) Recursos atuais: informações sobre os recursos disponíveis (materiais, humanos ou financeiros) investidos no tempo presente na execução de uma política. Parcerias entre instituições públicas e empresas privadas também estão envolvidas. 7) Ações planejadas: previsão de procedimentos e ações em escalonamento temporal. 8) Recursos planejados: relaciona-se ao planejamento de recursos e ações a serem empregadas para a realização da política pública no futuro determinado. 9) Eficiência: inclui informações sobre o funcionamento interno de determinada política pública, considerando-se o efeito do investimento e recursos utilizados em relação aos resultados alcançados. 10) Eficácia: aqui, o que se pretende avaliar é o resultado objetivo da implantação de um política, em relação a objetivos e ferramentas propostas. 11) Impacto (efetividade): avalia-se se determinada política obteve êxito ou fracasso em sua aplicação, o que depende do impacto social gerado. 12) Custo-efetividade: relaciona-se às informações sobre escolhas de ações 
possíveis comparadas às ações efetivamente obtidas. 13) Satisfação do usuário: compreende informações, sugestões e opiniões dos usuários, apuradas através de pesquisas de opinião, sondagens etc. 14) Equidade: relaciona-se à distribuição com justiça social dos benefícios, de acordo com as especificidades dos usuários.

Cada página web analisada recebeu os indicadores: '0' quando inexiste informação relacionada às categorias descritas acima; ' 1 ' quando há informação superficial (até 200 caracteres com espaços); e '2' quando há presença de informações mais aprofundadas. $\mathrm{O}$ nível máximo de dados sobre uma política, portanto, somaria 28 pontos (14 categorias X 2 pontos possíveis), o que indicaria a presença de informação de qualidade, plural, abrangente e contextualizada, considerada necessária ao exercício do direito à informação sobre gestão pública. O número de pontos efetivamente contabilizado para cada página web analisada, quando considerado em relação ao total possível de 28 pontos, gerou um valor percentual, denominado Índice de Qualidade de Informação (IQI).

\section{Resultados e discussão}

Foram avaliadas 84 páginas web sobre políticas públicas da área de saúde, das quais 31 foram também foram objeto de matérias disponíveis no YouTube. Nesta mídia, o IQI detectado foi de $34 \%$, o que indica que os dados disponíveis na plataforma representaram cerca de um terço do que, no contexto teórico-metodológico da pesquisa, foi considerado informação necessária à caracterização abrangente e plural de uma política pública. No YouTube, as categorias menos frequentes foram 'metas', 'satisfação do usuário', 'impacto (efetividade)' e 'recursos planejados', ao passo que 'custo-efetividade' e 'equidade' não apresentaram informações relacionadas. Nas mídias Facebook, Twitter e Orkut, o IQI foi de 28,5\%. As categorias menos frequentes foram 'metas', 'recursos planejados' e 'equidade'. Já 'custo-efetividade' e 'satisfação do usuário' não obtiveram informações relacionadas. As categorias mais frequentes em toda a amostra de políticas de saúde foram 'ações atuais' e 'recursos atuais'.

Referentes à temática ambiental, foram analisadas 34 páginas web com informações sobre políticas públicas, das quais seis também foram objeto de matérias disponíveis no YouTube, mídia em que o IQI detectado foi de 40\%. As categorias menos frequentes foram 'recursos planejados', 'antecedentes' e 'equidade'. Já 'custo-efetividade' e 'satisfação do usuário' não obtiveram informações relacionadas. Nos textos acessados através das mídias 
Facebook, Twitter e Orkut, o IQI foi de 30\%. As categorias menos frequentes foram 'satisfação do usuário', 'equidade', 'recursos planejados', 'impacto (efetividade)' e 'diagnósticos', ao passo que 'custo-efetividade' não obteve informações relacionadas. Considerando-se o total da amostra de informações sobre políticas públicas ambientais, as categorias mais frequentes foram 'eficiência' e 'ações atuais'.

Da área de assistência social, foram analisadas 44 páginas web, das quais nove também foram objeto de matérias no YouTube. O IQI detectado na mídia audiovisual foi de $35 \%$. As categorias menos frequentes foram 'recursos planejados' e 'objetivos'. Já 'custoefetividade' e 'satisfação do usuário' não obtiveram informações relacionadas. Nas mídias Facebook, Twitter e Orkut, o IQI registrado foi $29 \%$. As categorias menos frequentes foram 'satisfação do usuário', 'impacto (efetividade)' e 'recursos planejados'. 'Custo-efetividade' não obteve informações. De modo geral, as categorias mais frequentes foram 'eficiência', 'ações atuais' e 'recursos atuais'.

Da área de educação, foram analisadas 69 páginas web, das quais oito também foram objeto de matérias no YouTube, mídia na qual foi detectado o IQI de 35\%. A categoria menos frequente foi 'equidade', ao passo que não houve informações em 'impacto (efetividade)', 'custo-efetividade' e 'satisfação do usuário'. Nas mídias Facebook, Twitter e Orkut, o IQI apurado foi de $34 \%$. As categorias menos frequentes foram 'satisfação do usuário', 'impacto (efetividade)' e 'recursos planejados'. Já 'custo-efetividade' não obteve informações relacionadas. De forma geral, as categorias mais frequentes foram, novamente, 'eficiência', 'ações atuais' e 'recursos atuais'.

Tomando-se em consideração toda a amostra de 231 textos noticiosos acessados através dos perfis oficiais do governo paulista nas mídias YouTube, Facebook, Twitter e Orkut com informações sobre políticas das áreas de saúde, meio ambiente, assistência social e educação, nota-se que as categorias mais frequentes foram 'ações atuais', 'recursos atuais' e 'eficiência', o que sugere limitações no foco dos textos noticiosos sobre políticas públicas repercutidos através das mídias sociais oficiais, que se mostraram centrados em ênfases imediatistas e circunscritas aos efeitos mais visíveis das ações de governo nessa área, com escassas contextualizações sobre seus aspectos mais abrangentes.

De maneira generalizada para toda a amostra das quatro áreas de políticas analisadas, nota-se que 'metas', 'recursos planejados' e 'equidade' foram as categorias menos frequentes, enquanto informações sobre 'custo-efetividade' e 'satisfação do usuário' estiveram ausentes. 
'Recursos planejados' e 'metas' estão relacionados ao planejamento de políticas. A omissão de tais dados pode ser atribuída ao possível receio de seus gestores em disponibilizar informações que possam futuramente municiar pressões por resultados e prazos. Já a escassez de informação sobre 'equidade' pode estar ligada à dificuldade de os gestores públicos elaborarem ponderações sobre os efeitos mais duradouros das políticas sobre a resolução de desigualdades regionais. A ausência de 'custo-efetividade' pode ser relacionada à dificuldade dos gestores em descortinar o cenário mais complexo no qual as políticas foram desenhadas diante de alternativas possivelmente preferidas por adversários. 'Satisfação do usuário' pode estar ausente devido à relativa inexistência de procedimentos regulares de consulta e busca de opiniões sobre a qualidade dos serviços públicos entre os usuários.

Quanto às demandas de informação postadas pelos usuários nas redes sociais oficiais do governo paulista no período analisado, o total referente às quatro áreas de políticas selecionadas foi de 104 solicitações, das quais 71 foram encontradas no Twitter e 33 no Facebook. Embora exista no YouTube a possibilidade de usuários comentarem vídeos do governo e fazerem solicitações, o recurso não foi utilizado com essa finalidade. E, apesar do Orkut dispor de um mural no qual solicitações poderiam ser postadas, também não se verificou o uso nesse sentido.

A área de política pública mais demandada pelos usuários foi a educação, com $46 \%$ do total das solicitações no período, seguida por saúde (30\%), assistência social (18\%) e meio ambiente (6\%). Na área de educação, mais de 50\% das solicitações de usuários do Facebook vieram de perfis de usuários que se apresentaram como professores da rede pública de ensino, em relação a reivindicações salariais e trabalhistas. No Twitter, mais de $70 \%$ das solicitações referem-se a demandas por materiais e infraestrutura nas escolas.

$\mathrm{Na}$ área de saúde, mais de $80 \%$ das postagens no Facebook são reclamações sobre a qualidade do atendimento no sistema público, abrangendo reivindicações por consultas de especialidades médicas, medicamentos e tratamentos, além de questionamentos sobre o investimento no setor.

$\mathrm{Na}$ área de assistência social, tanto no Facebook como no Twitter, em média 85\% das solicitações se dirigem à falta de água, luz e saneamento básico. A respeito de meio ambiente, em ambas as mídias $90 \%$ dos usuários questionam o governo sobre sua capacidade de investir na recuperação do meio ambiente em ações de preservação do ar e das águas. 
Os números permitem apontar que o Twitter tende a ser a rede social através da qual o governo estadual constrói uma imagem de disponibilidade e abertura aos cidadãos. Neste sentido, a conta oficial nessa mídia pode ter assumido funções que seriam usualmente desempenhadas por uma ouvidoria pública, ao oferecer um meio de recepção e encaminhamento de questionamentos sobre a qualidade dos serviços públicos. No entanto, verificou-se a tendência de padronização do atendimento: em $85 \%$ das respostas, o gestor oficial apenas oferece um link para seção do portal estadual com uma resposta cabível à demanda do usuário. Cerca de $20 \%$ das respostas são idênticas.

No Facebook, não foram verificadas respostas às solicitações dos usuários no mural oficial. O retorno do governo pode ter sido encaminhado via mensagem direta ao solicitante; não foi possível saber se os usuários foram contemplados, devido à limitação característica do desenho da pesquisa, centrada no estudo das mídias sociais governamentais e não nas atividades dos usuários.

\section{Recomendações e considerações finais}

À luz dos resultados do estudo aqui descrito, notamos que muitos governos investiram em seus perfis nas mídias sociais YouTube, Facebook, Twitter e Orkut como forma de compor um índice unificado para conduzir o acesso a informações disponíveis em textos noticiosos sobre fatos e acontecimentos recentes, relacionados à diversidade de políticas públicas executadas nas várias áreas de gestão pública.

A postagem nas mídias sociais funciona como um título que atrai a leitura para uma abordagem mais ampla sobre determinada ação sistemática de governo. Em um curto período, são postadas dezenas de links para textos produzidos pelas assessorias de comunicação pública para divulgar fatos pertinentes à execução de políticas públicas, geralmente aqueles que resultam em benefícios imediatos aos cidadãos, como serviços públicos nas áreas de assistência social, saúde, educação e meio ambiente.

Cabe ressaltar que a produção dessas páginas pode não ter relação com sua posterior citação nas mídias sociais. No entanto, as mídias são utilizadas como porta de acesso à informação antes dispersa por amplos portais eletrônicos de governo. Quando o foco de estudo se concentra na carga cognitiva de dados sobre políticas públicas disponível ao usuário que se sirva do perfil de um governo nas mídias sociais para se informar, a questão de 
pesquisa se torna investigar qual é, afinal, a qualidade da informação sobre gestão pública à qual as mídias se tornam instrumento de acesso $^{2}$.

De forma geral, as páginas web com informações sobre políticas públicas das áreas de assistência social, saúde, educação e meio ambiente obtiveram baixo Índice de Qualidade da Informação (IQI), de acordo com os critérios adotados pela pesquisa. Em média, o IQI apurado foi de $34 \%$, o que significa que os dados disponíveis nos textos noticiosos acessados através das mídias sociais YouTube, Facebook, Twitter e Orkut possuem cerca de um terço do que, no contexto teórico-metodológico da investigação, foi considerado informação necessária para a caracterização abrangente e plural de uma política pública.

Os vídeos publicados pelo governo de São Paulo em sua conta oficial no YouTube sobre a área de meio ambiente alcançaram o IQI mais elevado, com 40\%, e as políticas acessadas através das mídias Facebook, Twitter e Orkut sobre a área de saúde foram as que registraram o menor IQI, com 28\%. Embora note-se uma diferença relativamente pequena entre estes números, o pior desempenho das informações sobre a área de saúde pode ser percebido como incômodo para os gestores públicos, considerando-se que a demanda por saúde é uma das mais prementes da atualidade e deveria ser acompanhada pela disseminação, por todos os meios possíveis, de esclarecimentos sobre os investimentos no setor.

Em consideração aos aspectos normativos revisados inicialmente sobre a comunicação pública digital capaz de contribuir para a consolidação da cidadania, é possível indicar, à luz dos resultados empíricos aqui descritos, que cabe, aos gestores das mídias sociais oficiais do governo do Estado de São Paulo, aprofundar as informações referentes ao planejamento e às medidas adotadas para colocar em prática as políticas públicas que formula e executa, em busca de mais transparência e responsabilização de mandatários. O planejamento implicaria a especificação de um roteiro de conteúdo para cada mídia social em que a comunicação pública será veiculada, de modo que atenda a cada público específico com informações adequadas, dispostas em torno das 14 categorias de avaliação aqui propostas.

A mensuração regular da performance dos governos nas mídias sociais é essencial para gerar conhecimento necessário à elaboração de estratégias de comunicação pública para a disseminação adequada de informações sobre políticas públicas e a formação da cidadania enquanto direito à informação. Esta pesquisa ofereceu uma contribuição para conhecer a qualidade da exploração das mídias digitais pelo governo do Estado de São Paulo. Novas

\footnotetext{
${ }^{2}$ Questões de pesquisa relacionadas foram exploradas em outro estudo (ROTHBERG, 2014).
} 
pesquisas serão necessárias para indicar a evolução do uso das tecnologias na comunicação pública digital ao longo do tempo, abrangendo ainda outros Estados brasileiros e esferas de governo.

\section{Referências}

BRANDÃO, E. P. Conceito de comunicação pública. In: DUARTE, J. (org.). Comunicação pública: estado, mercado, sociedade e interesse público. São Paulo: Atlas, 2007, p. 1-33.

BUSTAMANTE, J. Poder comunicativo, ecossistemas digitais e cidadania digital. In: SILVEIRA, S. A. (org.) Cidadania e redes digitais. Brasília, DF: Comitê Gestor da Internet no Brasil, 2010, p. 11-36.

COSTA, F. L.; CASTANHAR, J. C. Avaliação de programas públicos: desafios conceituais e metodológicos. RAP - Revista de Administração Pública, v. 37, n. 5, p. 969-92, 2003.

DUARTE, J. Instrumentos de comunicação pública. In: (org.). Comunicação pública: estado, mercado, sociedade e interesse público. São Paulo: Atlas, 2007, p. 59-71.

DUJISIN, R. A. Tres perspectivas para observar el gobierno electrónico. In: DUJISIN, R. A.; VIGÓN, M. A. P. (orgs.) América Latina Puntogob - casos y tendencias en gobierno electrónico. Santiago: FLACSO, 2004, p. 23-40.

FARIA, C. A. P. A política da avaliação de políticas públicas. Revista Brasileira de Ciências Sociais, v. 20, n. 59, p. 97-109, 2005.

GODOI, G. C. S. Cobrindo políticas públicas sociais: a importância conferida à agenda da infância e da adolescência. Media \& Jornalismo, n. 11, p. 29-50, 2007.

MARQUES, A. C. S. As intersecções entre o processo comunicativo e a deliberação pública. In: (org.) A deliberação pública e suas dimensões sociais, políticas e comunicativas: textos fundamentais. Belo Horizonte: Autêntica, 2009, p. 13-28.

MARQUES, F. P. J. A. Debates políticos na internet: a perspectiva da conversação civil. Opinião Pública, v. 12, n. 1, p. 164-187, 2006.

MATOS, H. A comunicação pública na perspectiva da teoria do reconhecimento. In: KUNSCH, M. M. K. (org.) Comunicação pública, sociedade e cidadania. São Caetano do Sul, SP: Difusão, 2011, p. 39-59.

MATOS, H. Comunicação pública, esfera pública e capital social. In: DUARTE, J. (org.). Comunicação pública: estado, mercado, sociedade e interesse público. São Paulo: Atlas, 2007, p. 47-58.

MONTEIRO, G. F. A singularidade da comunicação pública. In: DUARTE, J. (org.). Comunicação pública: estado, mercado, sociedade e interesse público. São Paulo: Atlas, 2007, p. 34-46. 
ROTHBERG, D. Democracia digital e redes sociais: Twitter como filtro de informação política. E-Compós (Brasília), v. 17, n. 1, p. 1-16, 2014.

Portais eletrônicos de governo e a contribuição da informação e da comunicação para a expansão da cidadania. In: Anais do $34^{\circ}$ Encontro Nacional da Associação de PósGraduação e Pesquisa em Ciências Sociais (Anpocs). Caxambu, MG, 2010.

SILVA, D. B. Transparência na esfera pública interconectada e dados governamentais abertos. In: SILVEIRA, S. (org.). Cidadania e redes digitais. São Paulo: Comitê Gestor da Internet no Brasil, 2010, p. 115-136.

SOUZA, C. "Estado do campo" da pesquisa em políticas públicas no Brasil. Revista Brasileira de Ciências Sociais, v. 18, n. 51, p. 15-20, 2003.

TREVISAN, A. P.; BELLEN, H. M. Avaliação de políticas públicas: uma revisão teórica de um campo em construção. RAP - Revista de Administração Pública, v. 42, n. 3, p. 529-50, 2008.

Original recebido em: 19/10/2013

Aceito para publicação em: 20/08/14

Sobre os autores

Danilo Rothberg

Bacharel em Comunicação, Mestre em Comunicação e Doutor em Sociologia pela Unesp (Universidade Estadual Paulista). Professor do

Departamento de Ciências Humanas da Faculdade de Arquitetura, Artes e Comunicação da Unesp (Bauru, SP).

Amanda da Silva Valença

Bacharel em Comunicação Social: Relações Públicas pela Unesp. Consultora do iTQi - International Taste \& Quality Institute (Bruxelas, Bélgica). 